\title{
Erratum to: Determinants of RFID Adoption in Malaysia's Healthcare Industry: Occupational Level as a Moderator
}

\author{
Suhaiza Zailani $^{1} \cdot$ Mohammad Iranmanesh $^{1}$ • Davoud Nikbin ${ }^{2}$. \\ Jameson Khoo Cheong Beng ${ }^{3}$
}

Published online: 16 June 2015

(C) Springer Science+Business Media New York 2015

Erratum to: J Med Syst (2015) 39:172

DOI 10.1007/s10916-014-0172-4

The original version of this article unfortunately contained an error. The affiliation of Davoud Nikbin in the proof is incorrect which should have been "Faculty of Business, Multimedia University, Melaka, Malaysia". The update is provided here as well.

The online version of the original article can be found at http://dx.doi.org/ 10.1007/s10916-014-0172-4.

$\triangle$ Mohammad Iranmanesh

iranmanesh.mohammad@gmail.com

1 University of Malaya, Kuala Lumpur, Malaysia

2 Faculty of Business, Multimedia University, Melaka, Malaysia

3 Universiti Sains Malaysia, Penang, Malaysia 